\title{
Alain Mabanckou, Demain j'aurai vingt ans
}

\section{Carminella Biondi}

\section{(2) OpenEdition}

\section{Journals}

\section{Edizione digitale}

URL: https://journals.openedition.org/studifrancesi/4845

DOI: 10.4000/studifrancesi.4845

ISSN: 2427-5856

\section{Editore}

Rosenberg \& Sellier

\section{Edizione cartacea}

Data di pubblicazione: 1 avril 2012

Paginazione: 195-196

ISSN: 0039-2944

\section{Notizia bibliografica digitale}

Carminella Biondi, «Alain Mabanckou, Demain j'aurai vingt ans», Studi Francesi [Online], 166 (I | LVI) |

2012, online dal 30 novembre 2015, consultato il 19 novembre 2021. URL: http://

journals.openedition.org/studifrancesi/4845 ; DOI: https://doi.org/10.4000/studifrancesi.4845

Questo documento è stato generato automaticamente il 19 novembre 2021.

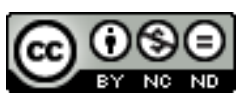

Studi Francesi è distribuita con Licenza Creative Commons Attribuzione - Non commerciale - Non opere derivate 4.0 Internazionale. 


\title{
Alain Mabanckou, Demain j'aurai vingt ans
}

\author{
Carminella Biondi
}

\section{NOTIZIA}

ALAIN MABANCKOU, Demain j'aurai vingt ans, Paris, Gallimard, 2010, pp. 381.

Il romanzo è ambientato à Pointe-Noire, capitale economica della Repubblica del Congo e città natale dello scrittore, negli anni '70 del secolo scorso. Il narratore, Michel, un ragazzino di 9-10 anni, racconta ciò che accade attorno a lui e descrive i protagonisti dei fatti che racconta e i loro comportamenti. Si tratta ovviamente di avvenimenti e comportamenti che nella maggior parte dei casi non capisce, che spesso gli sembrano misteriosi, assurdi o ridicoli e dei quali si sforza comunque, sempre, di dare un'interpretazione, con effetti spesso esilaranti. Ma queste storie, che il filtro di uno sguardo ingenuo rende apparentemente bizzarre e che talvolta sono davvero bizzarre ai nostri occhi di lettori occidentali indipendentemente dallo sguardo del narratore, ricostruiscono comunque in maniera efficace il modo di vita di una grande città congolese e più in generale della Repubblica del Congo allora guidata dal marxista Marien Ngouabi, salito al potere nel 1968 e assassinato nel 1977. Uno stato che si vorrebbe moderno, fondato su principi razionali, ma nel quale irrompono a guidare e a condizionare i comportamenti delle persone credenze e forze oscure che a volte terrorizzano il bambino, altre volte lo trovano scettico, seppur consenziente per quieto vivere o per non recare dolore. La storia più emblematica di questo doppio registro (moderno e arcaico) che guida la vita degli abitanti di Pointe-Noire e influenza pesantemente quella del bambino ha come fulcro una fantomatica clé che dovrebbe guarire la sterilità di sua madre Pauline. Dopo avere inutilmente fatto ricorso ai ritrovati della scienza, consultando medici neri e bianchi (questi ultimi rappresentano la scienza ai più alti livelli agli occhi degli abitanti), i genitori del ragazzo decidono di rivolgersi ad un «féticheur» che individua subito il male e suggerisce la soluzione: la porta del ventre della madre è chiusa da una chiave detenuta dal figlio Michel, che l'ha 
nascosta per rimanere figlio unico. La soluzione è facile: coccolare il ragazzo, riempirlo di attenzioni e di regali per farsi dare la misteriosa chiave. Stupito da tante attenzioni e da doni di cui non si spiega la ragione, Michel è infine informato dall'amico Lounès del responso dello stregone: dapprima nega di possedere la chiave, poi capendo che è inutile perché nessuno ci crede, se ne procura una. Il libro si conclude prima che conosciamo gli effetti della chiave, ma il suo dono alla madre ha comunque riportato la gioia in famiglia e Michel può finalmente guardare al futuro, a quando avrà vent'anni, come recita il titolo, con serenità. L'episodio rende bene il clima degli anni '70 in questo stato congolese che aveva adottato l'ideologia comunista e in cui due mondi cercavano difficilmente di convivere. Rende anche bene le infinite stranezze che in questa realtà composita colgono gli occhi di un ragazzino curioso che si sforza di trovare la sua strada evitando il più possibile i pericoli che la attraversano, trovando spesso soluzioni ingegnose.

2 Ma quello di Michel non è un universo chiuso, arroccato sui piccoli problemi quotidiani: «Le soir papa Roger se branche sur La Voix de l'Amérique, une radio qui donne les informations en français depuis l'Amérique» (p. 82). Attraverso le parole del giornalista Roger Guy Folly, il mondo irrompe così ogni sera nella vita di Michel che si commuove sullo Shah di Persia, cacciato dal suo paese e rifiutato da tutti i paesi del mondo nonostante sia malato di cancro, su Madre Teresa di Calcutta, mentre getta anatemi su Khomeini, Idi Amin Dada, Bokassa e su tutti gli uomini «cattivi» che fanno soffrire altri uomini, ricostruendo così a modo suo la storia del suo tempo. Lo sguardo del bambino, come nella famosa favola, vede «il re nudo» e ce lo mostra in tutta la sua arroganza ma anche nella sua fragile comicità. Poi ci sono i libri che contribuiscono anch'essi ad aprire, sia pure in forma inattesa, orizzonti sconosciuti, in particolare uno: Une saison en enfer di Rimbaud, appena sfogliato da Michel che rimane sì colpito da qualche frase misteriosa, ma soprattutto dalla biografia e dall'immagine dell'autore (riprodotta in quarta di copertina), con il quale si sente in sintonia instaurando un dialogo quanto mai fecondo che lo aiuta anche a superare alcune difficoltà e gli permette, tra l'altro, di riottenere l'amore perduto della sua amichetta Caroline.

Il linguaggio ingenuo del bambino rende gradevole la lettura e diverte, ma diverte alla maniera dei Persiani di Montesquieu, svelando l'assurdo di ciò che l'abitudine ci fa vedere come normale. 